\title{
The Impact of Electronic Word of Mouth on Brand Evaluation Leading to Brand Attachment: A Comparative Study on Consumer Electronics and Cosmetic Brands in Sri Lanka
}

\author{
Madhusanka J.D.T. ${ }^{1}$, Weerasiri R.A.S. ${ }^{2}$, Karunarathne W.V.A.D. ${ }^{3}$ \\ ${ }^{1}$ Rajarata University of Sri Lanka \\ ${ }^{2,3}$ University of Kelaniya, Sri Lanka \\ 1jdtmadhusanka@gmail.com, ${ }^{2}$ sudath@kln.ac.lk, ${ }^{3}$ anurawvadk@kln.ac.lk
}

\begin{abstract}
The traditional medium of communication has been changed with the invention of digital technologies and World Wide Web as a result of it conventional word of mouth has converted in to electronic word of mouth communication. Sharing Opinions about products services and brands has a created a new trend in the social media. This raises the need to study how companies can measure the effects of e-WOM communications and how e-WOM compares itself with other forms of marketing communication and branding. Measurement items are adapted from existing scales found in the marketing literature. The scales are evaluated for reliability, convergent validity, and discriminant validity using data collected in the survey. A structural equation modeling procedure is applied to the data analysis. The research model was tested empirically using a sample of 400 respondents who had experience within online communities of customers during the period of research. Argument quality dimension of electronic word of mouth reported highest impact on consumer brand attachment. The study found that e-WOM is one of the most effective factors influencing brand evaluation and brand attachment of brands in consumer electronic industry and cosmetic industry.
\end{abstract}

Keywords: Electronic word of Mouth, Brand Evaluation, Brand Attachment

Copyright: ( 2020 Madhusanka J.D.T, Weerasiri R.A.S, Karunarathne W.V.A.D. This is an open access article distributed under the Creative Commons Attribution License, which permits unrestricted use, distribution, and reproduction in any medium, provided the original work is properly cited.

Correspondence: jdtmadhusanka@gmail.com

ORCID of authors: Madhusanka J.D.T. - (D) https://orcid.org/0000-0002-5057-8800

Weerasiri R.A.S. - (D) https://orcid.org/0000-0002-5368-2688

DOI: http://doi.org/10.4038/kjm.v9i2.7641 


\section{Introduction}

The advent and expansion of the Internet have broadened the consumer choice of collecting product and service related information, by comprising other consumer evaluations, displayed on the Internet and provided customers with chances to deliver their specific consumer-related advice (e-WOM) by participating in digital based media (Hennig-Thurau et al., 2004). With the advantage of Internet-based technologies, information is no longer controlled only by large news media institutions or large communications and media service providers. Everyone can use the Internet to share their ideas and experiences about goods and services with thousands of people and influence the purchasing decisions of others through Ewom. (Duan, Gu and Whinston, 2008).

Consumer reviews on products and brands are one of the most important forms of electronic word of mouth. (Schindler and Bickart, 2005; Sen and Lerman, 2007), for many consumers, searching for online product reviews by collecting preproduction and consumption information has become an increasingly common practice. (Adjei et al., 2009; Zhu and Zhang, 2010) and develop Brand Attachment (Zhangand Tran, 2009). In addition, when it comes to modern businesses, branding is considered the primary capital of many industries.

The complex characteristics of goods as well as the value of the information associated with them are difficult to assess as they can only be evaluated after using, trying or understanding their content. In other words, many technological and beauty products are ones that consumers should use and enjoy before assessing the quality and positioning of their ideal product (Bounie et al., 2005).

Although there has been extensive research on the impact of EWOM on brand attachment in recent years compared to other decades, there are still a number of unresolved issues regarding this theme. Research shows that consumers are motivated to read and write on e-WOM for personal benefits and social benefits based on economic factors when making decisions related to purchasing goods and services. It is believed that it will definitely affect the brand attachment. (Hennig-Thurau and Walsh, 2003). However, little is known about how and to what extent Ewom affects brand attachment in the Sri Lankan context in relation to certain types of goods and services. The main purpose of this study is to comparatively evaluate the impact of e WOM on Brand Attachment in the consumer electronics industry and the cosmetic industry. The study also helps marketers by providing an understanding of consumers' attitudes and behaviors by gaining a deeper understanding of consumers' attitudes and Marketers can use them to better respond and target those customers in order to overcome the barriers to customer choice.

\section{Literature Review and Identified Research Gap}

Researchers have long focused on the construct E-WOM. Many previous researchers have pointed out theoretically that it has a unique relationship to branding. Basically, this research is limited to a few established theories and models used in the field of study and will support the results of structured questionnaire with respondents.

With the help of brand attachment theory, the researcher will analyze and explain how to identify a brand in the mind of the consumer in order to gain a deeper understanding of how a consumer interacts emotionally with a brand. This explains the brand evaluation developed (Keller, 2007).

The theory of self-expansion is used to further analyze the consumer mind as well 
as to distinguish the psychological significance of an attachment. The theory emphasizes that each individual seeks to expand his or her self-expansion, and that such expansion requires close relationships that include "others within oneself." (Patwardhan \& Balasubramanian, 2011). This study was conducted to find out the consumer angle on brand attachment and what they want to buy back that brand and maintains a sustainable close relationship with the brand for a long time. How companies create a beloved brand is an important point that many researchers have focused on before.

Many have argued that companies should accurately identify the impact of Ewom, both negative and positive.

Looking at the current business world, the researcher sees that consumers are increasingly relying on online information generated by other consumers to make brand attachment decisions and purchase decisions regarding future product purchases. (Hu, et al., 2011). Brand evaluation as well as information exchange, ideas and attitudes in modern business models powered by technology have been greatly influenced by the online media. (Mangold \& Faulds, 2009). Digital platforms are on the rise in the Sri Lankan context and already have hundreds of millions of registered users. (Romero, et al., 2011). One of the fastest growing and most popular Internet usage trends for Internet users is having at least one or more SNS accounts.

Furthermore, digital flat forms and social networking sites allow marketers to engage in two-way communication with online customers using personalized messages and product-related content. (Dunne, et al., 2010).

The 21 st century has marked the rapid and continuous growth of digital marketing with the advancement of new technologies. (Mangold \& Faulds, 2009), and especially SNS and messages transmitted through those sites (Trusov, et al., 2009).

Online media and websites are an ideal platform for electronic word of mouth as consumers share information and experiences related to brands through their online social networks. (Vollmer \& Precourt, 2008 cited in Chu \& Kim 2011). In the digital media space, SNS connections already exist within the customer's installed networks and can therefore be considered more reliable than the unknown users found on other digital media platforms. (Chu \& Kim, 2011). When exchanging electronic word of mouth openings, a person can become a commentator, seeker and transmitter. In Social networking sites, Idea seekers seek trusted recommendations from friends and commenters share ideas about products with other customers. Digital marketing, social media and EWOM are gaining importance all over the world. Sri Lanka too is not far behind. The above positive trend is an enhancing tool for EWOM and therefore it is clear that they are useful platforms as business companies can reach out to many current and potential customers. Although WOM is an essential component of small and medium-sized businesses, most of them still do not use the good features of digital media and electronic word of mouth for their business. However, in order to companies for take advantage of eWOM, they must obtain customer information; why they interact with e-wom in SNS and how they affect it.

By understanding how consumers' eWOM behavior influences brand attachment decision making, marketing-related managers can incorporate online media into their integrated marketing communications. (Chu \& Kim, 2011). Therefore, in order for businesses and business administrators to control and reap the benefits of eWOM, they must understand the mechanisms behind it and 
properly understand the standards of customer behavior.

Understanding how eWOM is affecting customers through web technology is a strategy that can be used to train organizations to make the most of this phenomenon. The literature review identified the practice gap after a proper study. That is, through the online media, it was observed how the electronic word affects consumer brand evaluation which leads to brand attachment. Based on this research gap, research hypotheses and a research model were developed. Empirical data were collected using a questionnaire.

\section{Conceptual Framework}

In order to test empirically the effect of EWOM on brand attachment, a conceptual model was developed based on the reviewed literature. In this conceptual model, the electronic word of mouth was the independent variable and the brand evaluation construct was identified as the mediating variable. Brand attachment was the dependent variable. Conceptual framework is included under the Appendix A.

\section{Methodological Overview}

Under the research philosophy Epistemology is Positivism and ontology is realism. Research Purpose was confirmatory correlational research design. This quantitative study was conducted with the deductive approach. The data collection method was the survey; in here structured questionnaire has been use with the support of online data collection process. Sample unit identified as "Person who have computer literacy and internet accessibility and engaged in an e-wom related activity within last 12 months". Then the Target population considered as all members of the eWOM communities in Sri Lanka who have the computer literacy and online accessibility; estimated population is 6.0 Million. Sample size limited to 400.According to the Krejcieand Morgan (1970) the minimum requirement for sample is 384. Sampling Design was probability sampling design because assessing differential parameters in subgroup of population (Sekaran\& Bougie, 2016). Under this Proportionate stratified random sampling has been used. In the section of data analysis Descriptive analysis and inferential analysis were conducted with the support of Spss and Amose version 23. Soft wares.

In this research, Churchill's (1979) approach to questionnaire preparation was followed. There are three main hypotheses of the proposed conceptual model examine the relationships between the eight constructs. These constructs have been converted into operational items.

\section{Population and Sampling}

A population is a group of individuals, objects, or items that are sample is taken for measurements during the research (Singh, 2007, p. 87). For the current study, the population is the "Internet Users in Sri Lanka who have computer literacy and online accessibility" - an estimated population of 6.0 Million. The present study operationally defines the "unit of analysis" as a local individual of Sri Lanka, who has computer literacy and internet accessibility and actively engaged in an e-wom related activity within the last 12 months. The study adopts the crosssectional time horizon; data is collected at a single time from the cases defined. This approach provides the total number of individuals within a country who can reach the Internet at home, via any device type (computer or mobile) and connection. The percent of the population with Internet access (i.e., the penetration rate) helps gauge how widespread Internet use is within a country. This research study has been used the probability sampling; namely, Proportionate Stratified 
Samplings. (Sekaran\& Bougie, 2016). Stratified random sampling is a process of sampling that includes the separation of a population into smaller groups known as strata. In stratified random sampling, or stratification, the strata are determined based on members' shared qualities or characteristics.

\section{Data Analysis}

\section{Sample Profile}

Data collection for the research was carried out from 1st of August 2019 for a period of one month. 425 questionnaires were collected from respondents using structured questionnaire. The questionnaires were distributed over the internet platforms. The questionnaires were checked carefully before entering the data using SPSS. Out of the 425 questionnaires collected, only 400 were used; 25 were discarded and considered unusable due to the huge amount of missing data resulting from incomplete sections or missing pages. According to the requirement of the structural equation modelling (SEM) used in the data analysis, the minimum sample size required for this is 300 (Hair et al., 2010; Kline, 2005; Tabachnich and Fidell, 2006).Therefore, this number of usable questionnaire is considered acceptable.

\section{Table 01: Demographic Information of Sample Profile}

Gender distribution of sample profile

\begin{tabular}{|c|c|c|}
\hline & Frequency & Percent \\
\hline Male & 199 & 49.8 \\
\hline Female & 201 & 50.2 \\
\hline Total & 400 & 100.0 \\
\hline \multicolumn{3}{|c|}{ Age Distribution of the sample profile } \\
\hline & Frequency & Percent \\
\hline$<24$ & 23 & 5.8 \\
\hline $25-30$ & 114 & 28.5 \\
\hline $31-35$ & 128 & 32.0 \\
\hline
\end{tabular}

\begin{tabular}{lll} 
'36-40 & 87 & 21.8 \\
$41-45$ & 34 & 8.5 \\
$46<$ & 14 & 3.5 \\
Total & 400 & 100.0 \\
\hline \hline Income Distribution of sample profile \\
\hline \hline \multicolumn{4}{c}{ Frequency Percent } \\
\hline$<15000$ & 14 & 3.5 \\
$15000-25000$ & 53 & 13.3 \\
$25000-35000$ & 179 & 44.8 \\
35000 & 154 & 38.5 \\
Total & 400 & 100.0 \\
\hline \hline Respondents' Education qualifications \\
\hline \hline \multicolumn{4}{c}{ Frequency Percent } \\
\hline No formal education & 1 & .3 \\
Primary education & 5 & 1.3 \\
Passed GCE O/L & 15 & 3.8 \\
Passed GCE A/L & 154 & 38.5 \\
Diploma & 97 & 24.3 \\
Degree & 118 & 29.5 \\
Post Graduate & 10 & 2.5 \\
Total & 400 & 100.0 \\
\hline \hline Sourc: Main survey & $5 a t a$ & \\
\hline
\end{tabular}

Source: Main survey data

\section{Reliability Assessment (Cronbach's Alpha)}

Reliability assessment means the degree of the consistency between the measurement indicators of the construct is stable at any point of time, as well as free of errors (Kline, 2005).

The following table shows the results of the reliability test of the main survey. Those values indicate that all of the constructs have good reliability measures. Inter-item correlation and item - to - total correlations are more than the threshold values; 0.3 and 0.5 respectively. (Hair et al, 2010). Furthermore, Cronbach's alpha values for the constructs range from 0.909 to 0.974 . Therefore, it can be considered that those values lie within the acceptable range; it means the strength ranging from good to excellent. (Hairet al.2003). 
Table 02: Reliability test (Cronbach's Alpha) of the Main Survey

\begin{tabular}{lccc}
\hline Variable & $\begin{array}{c}\text { Cronbach's } \\
\text { Alpha value }\end{array}$ & $\begin{array}{c}\text { No. of } \\
\text { Dimensions }\end{array}$ & $\begin{array}{c}\text { No. of } \\
\text { Items }\end{array}$ \\
\hline E WOM & 0.937 & 5 & 31 \\
\hline Brand Evaluation & 0.956 & 5 & 29 \\
\hline Brand Attachment & 0.846 & 3 & 10 \\
\hline
\end{tabular}

Source: Main survey data

\section{Structural Equation Modelling}

Structural equation modelling (SEM) can be considered as multivariate analysis method. This technique is used in this research to explain relationships among specified constructs in the conceptual model. Under the SEM there are several methods to identify estimates for each parameter. Those are the named as; OLS (Ordinary least squares) GLS (generalized least squares), MLE (Maximum likelihood estimation). Ordinary least squares was the common method used in the early stage of using Structural equation modeling. However, that method subsequently replaced by Maximum likelihood estimation method. Moreover, generalized least squares technique and weighted least squares are currently available. But, Maximum likelihood estimation technique has become default method of Structural equation modeling due to its flexibility and robustness in the violation of the assumption named normality. (Hair et al. 2010). All of the assumptions of related to the multivariate techniques which are examined at the preliminary stage under the data analysis were acceptable. AMOS (Analysis of Moment Structures) v.23 is the statistical program used, having the feature of providing clear output, estimating missing data and analyzing data with the multigroups (Tabachnick and Fidell, 2006). The process for structural equation modelling includes two types of models: the measurement model, which is then converted to the structural model. Measurement model has been specified the indicators for every constructs and evaluate the construct related validity using confirmatory factor analysis. The structure model represents the interrelationships of variables between constructs to test the hypotheses (Hair et al., 2010).

\section{Measurement Model}

Measurement model validity depends on the evaluation of the research model's goodness of fit and the evaluation of the validity. Hence, the assessment of the "measurement model" validity has been conducted by following two steps. Those are the goodness of fit and validity evaluation. Those methods are commonly used by the previous scholars for evaluating the measurement model validity. It means; testing each dimensions separately where each latent variable was conducted independently. (Garver \& Mentzer. 1999) and testing all of the constructs to gather in one time. (Cheng. 2001).

\section{Structural Model and Hypotheses Testing}

The main purpose of conducting confirmatory factor analysis related to the measurement model support validity of measures through providing evidences for research model adequate fit \& construct validity. Then, to test the relationship between variables as hypothesized at the suggested theoretical model, measurement model was transformed to structural model. (Hairet al.2010). Structural equation modeling was specified by transformation of covariance between variables and into path estimates, hypothesized causal relationships. Exogenous variables, independent 
variables were identified and the relationships were identified and relationships between those variables were fixed at zero. As well as, for endogenous variables, outcomes were identified and error terms were to them since they were no fully explained. The initial Structural model, Modified structural model and the Alternative structural models have been illustrated under the appendix.

\section{Reporting Model Fit Indices of Original SEM and Alternative SEM Models}

This study tests mainly three (3) direct paths as hypothesized in the conceptual model. Firstly, researcher examines the hypotheses developed on direct paths by using estimated output derived from SEM -AMOS 23. As it suggested by Davis, et.al. (2013), researcher reports model fit indices of the improved hypothesized structural model before outlining the results of hypotheses testing (see Table below).

As per the indexes reported in the above table, original SEM model found essential model fit indices, however, some indexes were not found within the highly acceptable range (Davis, et.al.2013). Additionally, P-close value was not reported (0.000). Thus, model improvement steps were followed in line with the modification indices. Accordingly, alternative model meets the requirement of P-close within the rule of sample size $(\mathrm{N})>200$ (Hoelter, 1983) satisfying additional requirements for a perfect model fit. Thus, researcher concludes that alternative structural model meets required model fitness to test the hypotheses.

The informative tables related to the mediation effect testing has included under the appendices.

Table 03: Reporting Model Fit Indices; Original SEM Model and Alternative SEM Model.

\begin{tabular}{lrrrr}
\hline \multicolumn{1}{c}{ Indices } & $\begin{array}{c}\text { Results: } \\
\text { SEM } \\
\text { Original }\end{array}$ & Model Fit & \multicolumn{1}{c}{$\begin{array}{c}\text { Results: } \\
\text { SEM } \\
\text { Alternative }\end{array}$} & Model Fit \\
\hline CMIN/DF & 4.978 & Justifiable & 2.876 & Yes \\
\hline CFI 0.911 Yes 0.935 & 0.774 & No & 0.937 & Acceptable \\
\hline RAMSEA & 0.06 & No & 0.04 & Yes \\
\hline P-close & 0.07 & No & 0.000 & Acceptable \\
\hline
\end{tabular}

CMIN/DF: Chi-squared/degrees of freedom ratio, CFI: Comparative Fit Index, RMSEA: Root-Mean-Square Error of Approximation.

Source: Main survey data

\section{Findings}

\section{Argument quality influence on Brand attachment}

Argument quality can be described as "the persuasive strength of arguments embedded in an informational-message". This means that the ability to persuade the recipient position of the message to convince his or her image, which they have embedded in mind regarding a particular product, service or brand. In line with the findings of this research, Cacioppo, (1983), also noted that in the social media context, argument quality affects the message receivers' attitudes. If the content of online reviews or messages is perceived or felt to be valid, the recipient of the message will generate a positive evaluation or attitude towards the 
products, services or brands related to those reviews. In that case, the argument contained in the message is considered credible.

Table 04: Hypotheses Testing Results

\begin{tabular}{|c|c|c|c|c|c|c|c|}
\hline \multirow[b]{2}{*}{ 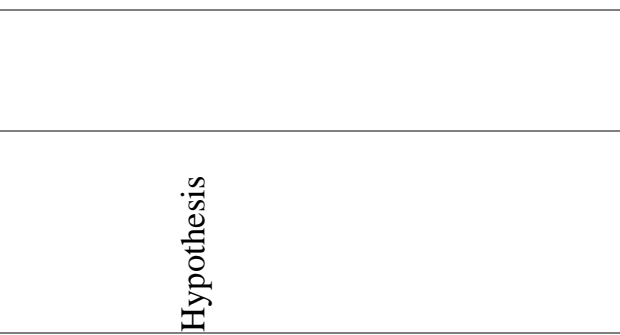 } & \multicolumn{3}{|c|}{ Total Data set } & \multicolumn{2}{|c|}{$\begin{array}{l}\text { Consumer } \\
\text { Electronic } \\
\text { Industry }\end{array}$} & \multicolumn{2}{|c|}{$\begin{array}{l}\text { Cosmetic } \\
\text { Industry }\end{array}$} \\
\hline & 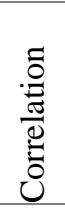 & 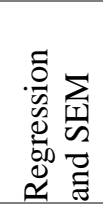 & 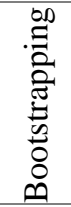 & 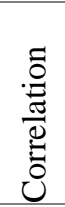 & 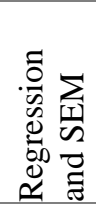 & 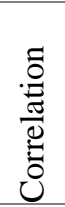 & 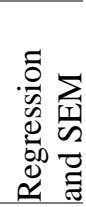 \\
\hline $\begin{array}{l}\text { H1 } \\
\text { EWOM } \rightarrow \text { Brand Attachment }\end{array}$ & $\mathrm{A}^{*}$ & $\mathrm{~A}^{*}$ & -- & $\mathrm{A}^{*}$ & $\mathrm{~A}^{*}$ & $\mathrm{~A}^{*}$ & $\mathrm{~A}^{*}$ \\
\hline $\begin{array}{l}\text { H1a } \\
\text { Argument quality } \rightarrow \text { Brand Attachment }\end{array}$ & $\mathrm{A}^{*}$ & $\mathrm{~A}^{*}$ & -- & $\mathrm{A}^{*}$ & $\mathrm{~A}^{*}$ & $\mathrm{~A}^{*}$ & $\mathrm{~A}^{*}$ \\
\hline $\begin{array}{l}\text { H1b } \\
\text { Source credibility } \rightarrow \text { Brand Attachment }\end{array}$ & A* & $\mathrm{A}^{*}$ & -- & $\mathrm{A}^{*}$ & $A^{*}$ & $\mathrm{~A}^{*}$ & A* \\
\hline $\begin{array}{l}\text { H1c } \\
\text { Source attractiveness } \rightarrow \text { Brand Attachment }\end{array}$ & $\mathrm{A}^{*}$ & $\mathrm{~A}^{*}$ & -- & $\mathrm{A}^{*}$ & $\mathrm{~A}^{*}$ & $\mathrm{~A}^{*}$ & $\mathrm{~A}^{*}$ \\
\hline $\begin{array}{l}\text { H1d } \\
\text { Source perception } \rightarrow \text { Brand Attachment }\end{array}$ & A* & $\mathrm{A}^{*}$ & -- & $\mathrm{A}^{*}$ & $A^{*}$ & $\mathrm{~A}^{*}$ & $\begin{array}{l}\mathrm{R} \\
* * *\end{array}$ \\
\hline $\begin{array}{l}\text { H1e } \\
\text { Source style } \rightarrow \text { Brand Attachment }\end{array}$ & A* & $\mathrm{A}^{*}$ & -- & $\mathrm{A}^{*}$ & $\begin{array}{l}\mathrm{R} \\
* * *\end{array}$ & A* & $\mathrm{A}^{*}$ \\
\hline $\begin{array}{l}\mathrm{H} 2 \\
\text { EWOM } \rightarrow \text { Brand Evaluation }\end{array}$ & $\mathrm{A}^{*}$ & $\mathrm{~A}^{*}$ & -- & $\mathrm{A}^{*}$ & $\mathrm{~A}^{*}$ & $\mathrm{~A}^{*}$ & A* \\
\hline $\begin{array}{l}\text { H3 } \\
\text { Brand Evaluation } \rightarrow \text { Brand Attachment }\end{array}$ & $\mathrm{A}^{*}$ & $\mathrm{~A}^{*}$ & -- & $\mathrm{A}^{*}$ & A* & $\mathrm{A}^{*}$ & $\mathrm{~A}^{*}$ \\
\hline $\begin{array}{l}\text { H4 } \\
\text { Mediating effect of Brand evaluation } \\
\rightarrow \text { EWOM and Brand Attachment }\end{array}$ & -- & $\begin{array}{l}\text { PA } \\
* *\end{array}$ & $\begin{array}{l}\text { PA } \\
* *\end{array}$ & -- & $\begin{array}{l}\text { PA } \\
* *\end{array}$ & -- & $\begin{array}{l}\text { PA } \\
* *\end{array}$ \\
\hline
\end{tabular}

A* = Accepted, $\quad \mathrm{PA}^{* *}=$ Partially Accepted, $\mathrm{R} * * * \quad=$ Rejected

Source: Main survey data

On the contrary, if the reviews on social networking sites seem to be invalid, then the message reader is negatively evaluated on the relevant products, services, and brands. It also means that information relating to the argument being reviewed was not credible. According to the analysis, consumers will establish the quality of an argument based on factors such as strength, comprehensiveness, accuracy, timeliness, and relevance.
Simply explained, the strength of the argument means that the capability of online reviews in persuading users. Information that is understandable, informative and has the appropriate width and depth can be identified as comprehensive. Accuracy can be identified by the correctness of the information presented. Up-to-date and current information reflects Timeliness. The extent to which the reviews are 
relevant and applicable is called relevance. Therefore, based on data analysis, it is important to identify appropriate recommendations. Since the quality of the arguments has a significant impact on decision-making related to brand attachment, the researcher suggests the following strategies to improve the quality of Internet-based arguments of social networks. Companies should actively get involved in some online consumer communities and provide all the relevant, accurate, actual, comprehensive and complete information about the brands. Online review sites could provide a review format and guidelines with appropriate product/service dimensions that allow reviewers to express both positive and negative feedbacks.

\section{Source Credibility Influence on Brand Attachment}

For managers, the foremost essential consideration for harnessing and leveraging eWOM should be the maintenance of credibility. By ensuring credibility, marketers stand a far better chance of leveraging peer-to-peer communications for monetary gain. Centering on the four modules of community, competence, content, and consensus should drive better firm-created content, replicating the tone, and enthusiasm of happy customers. The 'hard sell' and 'corporate speak' aren't elements of viral marketing and serve no purpose on social media. Instead, attention on community conversation, underpinned by reliable communications should enable managers to drive user engagement. Furthermore, the framework which describe the credibility is often employed by companies, and brand related researchers to spot the foremost suitable electronic word of mouth communications to leverage for promotional purposes like to pin to the highest of a brand's Social media page or to function consumer endorsements on the brands' websites. To enhance the source credibility, Marketers should attempt to identify "experienced social influencers" or "market experts" in social networking sites and encourage them to spread positive product information. Online retailers should increase cooperation with bloggers and social media opinion leaders. It is often done by providing hyperlinks to blogs or other websites that generate e-WOM or provide expert recommendations. Companies should encourage positive eWOM without engaging in unethical and deceptive practices. (E.g. eWOM manipulations). Increasing the supply of reviewers' information (e.g. profile information, and actual usage experiences) might validate the contributed review.

\section{Source Attractiveness Influence on Brand Attachment}

In this section, it's intended to debate the influence of source attractiveness, as identified by the info analysis. The source attraction is that the extent to which message receivers identified the source. Specifically, this study revealed that the source attractiveness of online reviews determines the perception towards brand attachment of the consumers, which has been shown to influence consumer decision-making also. Consistent with most of the respondents, the three antecedents that influence source attractiveness are the: similarity, familiarity, and likeability. The first signifier of these sequence means the resemblance shared by the message creator and communication receiver. Especially, analysis of the research reveals that buyers are more likely to perceive as credible such online reviews if they feel 
that the message is communicated by a communicator, almost like the opinions of the recipient. Familiarity is defined because the level of comfort that exists between the sender and receiver of an electronic word of mouth message. During this regard, further details are often stated if consumers conversant in relevant online reviews, that build trust in those consumer shared reviews. Likeability refers to the love developed by online reviews readers about the web source, the physical appearance of the source, or personal traits. In Cyberspace, when people like online reviews published by other customers, they perceive those sources as attractive sources. One among the only examples is that the Facebook Like button that's created by that website. Therefore, it's important to concentrate to the corresponding strategies because the analysis shows that the three main attributes of source attractiveness are similarity, and familiarity and likeability which their functional roles are critical factors within the effective brand evaluation and brand attachment. To reinforce the source attractiveness: Familiarity, similarity and likability are identified as important determinants. Therefore, when using marketing communications tactics like celebrity endorsement, communicators of an equivalent socio - demographic group might be wont to send messages to the EWOM communities. Creating online consumer opinion groups supported demographic categories and clusters also vital.

\section{Source Perception Influence on Brand Attachment}

The study results suggest that the marketplace for reviews is efficient which consumers are rational. Over the end of the day, a technique of recruiting reviewers to write well reviews of a vendor's own products and bad reviews of competitors' products is unlikely to succeed. Customers can identify the authenticity of a review. They now have the power to differentiate an honest reviewer from a nasty reviewer. Companies got to identify reviewers who have better reputations and have higher exposure. They ought to attempt to promote new products to them, expecting those reviewers will respond with favorable reviews. Those reviewers will usually act as early adopters and opinion leaders within the online consumer community. Their tastes and judgments will determine what products other customers will like better to use within the future.

\section{Source Perception and Social Tie}

Factors such as friends and family can be considered as strong tie sources. On the other hand acquaintances and strangers can be identified as weak tie. Based on research findings it can be mentioned that, the perceived tie strength influence the selection of those sources and those customers have various types of motivations for use of weak tie versus strong tie sources. In here the researcher found that more than $70 \%$ of respondents were likely to use knowledgeable friends, relatives, and acquaintances as sources of information in their product purchases.

\section{Source Style Influence on Brand Attachment}

The different reviews of electronic wordof-mouth, currently available on the online, shows that visual information of a product includes images, videos, motion pictures, and graphics. In consumers, social media practice, it's largely observable that online reviews are posted as a mix of texts and visual cues. It has 
been discussed within the literature review chapter that visual information stimulates information elaboration and increases the likelihood of knowledge retrieval in recall tasks. It has been further argued that both verbal and visual kinds of online information enhance the potential of understanding and perceived positive brand evaluation that leads to higher brand attachment. Not surprisingly, consumers are more likely to use pictorial information, like images, colors, or patterns to share personal experiences and feelings, during a situation that makes people more interested in watching multimedia graphics than reading text. Supported data analysis, it is often mentioned that review which are graphically presented, detailed, high volume, contrasted, highly recommended by most reviewers are often identified as highly accepted electronic word of mouth reviews. It is vital to specialize in strategies which can increase brand attachment by aggregate the source style.

To improve the source style following strategies could be used: Online platform owners should provide consumers with opportunities to include visual information in their electronic word of mouth communications surely kinds of goods and services. Especially in cosmetic industry. Emotions embedded in electronic word of mouth messages should be encouraged. Moreover, Retailers can create and provide standardized review forms for consumers to make reviews more helpful to readers.

\section{Electronic Word of Mouth Influence on Brand Evaluation}

The availability, reach, and straightforwardness of the web permit marketers and organizations to screen the online word of mouth communication almost their brands ceaselessly (Kozinets et al., 2010). Marketers might create suitable communication apparatuses to create buyers more learned around particular brand or band characteristics and attempt to alter a few of the negative affiliations that shoppers have around the brand or the item through online WOM. It is imperative to say that positive WOM and e-WOM play an imperative part in expanding customers' brand connection, making a favorable assessment of the company and its brand, and lessening limited time uses.

\section{Brand Evaluation Influence on Brand Attachment}

Modern marketers can move forward the brand assessment by expanding item assortment, upgrading item quality, advertising the items within the cost commendable of esteem, and wonderfully giving after deal administrations. These changes straightforwardly increment the connection towards the brands. In any case, companies with tall value brands ought to not depend on the benefits of tall brand assessment such as client dependability that can be found within the writing (Aaker, 1991; Agarwal and Rao, 1996; Keller and Lehmann, 2006). Instep, such companies ought to be mindful of the dangers of negative online WOM communication, since indeed tall brand value can be altogether weakened by negative online WOM and since such hindering impacts will gotten to be indeed more vital with expanding advancements in, and spread of, arrange innovation.

\section{Electronic Word of Mouth Influence on Brand Attachment}

The finding that online WOM communication can cause brand connection is especially critical for customer electronic items and makeup producers. Through portable web, which 
is getting to be progressively well known, clients can study online recommendations for the item they are curious about specifically at the point of buy, which might have solid effects on their brand related choices. In this manner, directors seem start point-of-sale exercises within the form of item trials with the objective of propelling online WOM communication by empowering buyers to make their claim impressions.

\section{Conclusion}

The reason of this consider is to pick up more understanding approximately the customer advanced communication behavior and buyer brand connection handle, particularly analyzing the impacts of online data and word of mouth communication towards shopper assessment of brands within the handle of building solid connections towards brands in corrective items and shopper electronic items. It moreover pointed to investigate the determinants that impact a consumer's word of mouth communications through electronic and online media as indicators of audits and brand assessment, which leads to brand connection, particularly when buying beauty care products or buyer electronic items. The appearance of the Web and World Wide Web enables electronic word of mouth communication between customers. In any case, at the same time, the developing ubiquity of online data moreover brings numerous concerns with respect to the e-WOM communications. Based on the current writing almost the e-WOM, five fundamental measurements are distinguished.

\section{Discussion}

Brand communication is being started by customers as compared to showcasing personals. Client produced substance is being created in different shapes like item recordings, item utilization dialogs, client item surveys, item photo and data sharing etc. A few of the common online stages which empowers creation and dissimilation of such substance are YouTube, Facebook, Twitter, Individual Blogs \& Web Pages, Wikipedia and numerous others. This makes shoppers dynamic and in charge of their media encounter, and in this way their level of inclusion here got to be much more when compared to conventional promoting. In numerous of the cases Brand communication is being started, kept up, controlled and indeed claimed by shoppers as compared to the marketers prior.

Advertiser has constrained control over communication compared to conventional showcasing. Other suggestion of this alter is the restricted control over communication advertiser has in current environment compared to days of solo conventional showcasing. In any case, this does not infer that advertiser has no control over UGC (Sort of online Wordof-Mouth Communication) or both of these work in segregation. The examination appears that more than 20 percent of online word of mouth (WOM) communication is affected by paid-media promoting and 32 percent of online WOM communications around brands is likely to contain references to publicizing. This reflects that promoting does impact online WOM and hence interaction between publicizing and online WOM is clear. Customers get together impacted by numerous source of data.

These discoveries are comparative to the discoveries of past inquires about is being done to investigate what drives customers to take part in online WOM (for e.g. Cheema and Kaikati, 2010; Daugherty, 
Eastin and Shinning, 2008 etc.) Be that as it may, it's too captivating to see how shoppers would mutually get impacted by numerous sources of data and encounters, which may incorporate online WOM (Online customer audits), conventional publicizing, as well as item trails and show. Impressive investigate has been done to get it person and together impacts of conventional data sources on shopper state of mind and behavior. Be that as it may, due to later advancement of modern data sources like online WOM, insufficient writing is accessible on how these impact customers. Even additional thing is research on joint processing of traditional as well as new sources of information, which definitely exists at market place.

Shopper interaction is consider and deliberate in online data sources. Be that as it may, the exceptionally fundamental nature of these data sources and the way shopper sees them within the current commercial center may well be diverse. For illustration, introduction to promoting for the most part happens by chance, though buyer interaction is ponder and deliberate in case of online data sources. Moreover, the level of association may varies when customers are uncovered to promoting jolt as compared whereas association or being uncovered to Online WOM or client created substance. This advance questions the suitability and appropriateness of conventional communication models and speculations (for e.g. Elaboration Probability Demonstrate, Data Integration Hypothesis, and Coordinates Data Reaction Demonstrate etc.) which have been utilized in such setting prior. Hence, these questions give a interesting region for this inquire about which are both significant and clarify for the inquire about.
EWOM can offer assistance to diminish instability and the sum of data that's included in making a decision. Consumers are now not inactive, but ended up dynamic data searchers. Hence, the analyst propose that making EWOM more central to Brand communication and to the improvement of promoting strategy. EWOM is spread by individuals who don't speak to a commercial offering source, so they are seen to have small intrigued in advancing the company and they have no coordinate pick up from modifying the truth in favor of the item or benefit.

Theoretical and Managerial Implications.

This study mainly contributes to the existing literature in different ways. This has provided a model that aims to understand the construct called brand attachment from evaluation of the brand which is based on electronic word of mouth communication. The researcher has explained the importance of this study by using nine key points.

First, this research study has contributed to the current marketing literature. Moreover, this provide proper understanding about electronic word of mouth and its influence on branding and future decision making. Additionally this study cover the scarcity of academic knowledge in this area and reveal the determinants of brand evaluation.

Second, this study explain the insides of the relative important which is related to the consumer brand evaluation which leads to brand attachments.

Third, it can be stated that this study goes beyond the impression of evaluation which was used with the prior research studies related to brand evaluation. The main focus of this study discussed the 
relationship between e-wom and brand attachment.

Fourth, the differences are identified and comparatively discussed in the overlapping terms which are reflecting brand evaluation and brand attachment

Fifth, this research study critically compared to different industries named consumer electronics industry cosmetic industry by using involvement theory. Hence it can be concluded that that the research evaluate comparative results on brand related literature.

Sixth, result of this study stands with the stream of previous researches for revealing significant mediating influence related to evaluations of brands and its impact to the relationship between e-wom and brand attachment.

Seventh, findings of this study reveal the importance of digital communication and opinions in developing an understanding which is related to customer brand attachment and their future bind decisions.

Eighth, despite the growing popularity and critical importance related to electronic word of mouth communication, the understanding of the e-wom phenomenon is remaining somewhat limited. The integrated knowledge about the principals and mechanisms related to electronic word of mouth constrain the ability to utilize technology oriented influential power of electronic word of mouth. Additionally, this study has been used the dual process theory under the context of consumer electronic brands and cosmetic brands in Sri Lanka. As well as it has been measured that the influence power of both informational and normative determiners on consumer brand evaluation
Understanding these specific concepts and relationships would clarify on how customers used information given under a review during an evaluation process. Moreover this research confirms the findings of previous researchers' opinions and support the influence of informational factors, including argument quality and source credibility.

Ninth, the digital based word of mouth communication has become a popular informational source for consumers and marketers. Since researchers focused on impact of e-wom on consumer brand related attributes such as brand evaluation and brand attachment, there is a specific need to understand how customers using digital flat-form based online opinions, whether those people understand the information embedded in online reviews, whether those people relay on online reviews to make different kind of brand evaluations and under what situations online review is likely to attach o brands. This research contributes to these emerging literature and theoretical areas by addressing these fundamental but heavily neglected research related questions.

\section{References}

Arndt, J. (1967). Role of product-related conversations in the diffusion of a new product. Journal of marketing Research, 4(3), 291-295. DOI: 10.2307/3149462

Awad, N. F., \& Ragowsky, A. (2008). Establishing trust in electronic commerce through online word of mouth: An examination across genders. Journal of Management Information Systems, 24(4), 101-121. DOI: 10.2753/MIS07421222240404

Bickart, B., \& Schindler, R. M. (2001). Internet forums as influential sources of 
consumer information. Journal of interactive marketing, 15(3), 31-40.

Brown, J., Broderick, A. J., \& Lee, N. (2007). Word of mouth communication within online communities: Conceptualizing the online social network. Journal of interactive marketing, 21(3), 2-20. DOI: 10.1002/dir.20082

Buttle, F. A. (1998). Word of mouth: understanding and managing referral marketing. Journal of strategic marketing, 6(3), 241-254. DOI: $10.1080 / 096525498346658$

Casaló, L. V., Flavián, C., \& Guinalíu, M. (2008). The role of satisfaction and website usability in developing customer loyalty and positive word- of- mouth in the e- banking services. International journal of bank marketing. DOI: 10.1108/02652320810902433

Cheung, C. M., \& Thadani, D. R. (2012). The impact of electronic word-of-mouth communication: A literature analysis and integrative model. Decision support systems, 54(1), 461-470. 10. DOI: 1016/j.dss.2012.06.008

Cheung, C. M., Lee, M. K., \& Rabjohn, N. (2008). The impact of electronic word-ofmouth: The adoption of online opinions in online customer communities. Internet Research: Electronic Networking Applications and Policy, 18(3), 229-247. DOI:

229-247.

\section{$10.1108 / 10662240810883290$}

Cvijikj, I. P., \& Michahelles, F. (2013). Online engagement factors on Facebook brand pages. Social network analysis and mining, 3(4), DOI: 843-861. 10.1007/s13278-013-0098-8

Dellarocas, C. (2003). The digitization of word of mouth: Promise and challenges of online feedback mechanisms.
Management science, 49(10), $\quad$ DOI: 1407-1424.

10.1287/mnsc.49.10.1407.17308

Doh, S. J., \& Hwang, J. S. (2009). How consumers evaluate eWOM (electronic word-of-mouth) messages. Cyber Psychology \& Behavior, 12(2), 193-197. DOI: $10.1089 / \mathrm{cpb} .2008 .0109$

Dunn, L., \& Hoegg, J. (2014). The impact of fear on emotional brand attachment. Journal of Consumer Research, 41(1), 152-168. DOI: $10.1086 / 675377$

Fedorikhin, A., Park, C. W., \& Thomson, M. (2008). Beyond fit and attitude: The effect of emotional attachment on consumer responses to brand extensions. Journal of Consumer Psychology, 18(4), DOI: 281-291.

10.1016/j.jcps.2008.09.006

Godes, D., \& Mayzlin, D. (2004). Using online conversations to study word-ofmouth communication. Marketing science, 23(4), 545-560. DOI: 10.1287/mksc.1040.0071

Goldsmith, R. E., \& Horowitz, D. (2006). Measuring motivations for online opinion seeking. Journal of interactive advertising, $\quad 6(2), \quad 2-14$. DOI:10.1080/15252019.2006.10722114

Grace, D., \& O'cass, A. (2005). Examining the effects of service brand communications on brand evaluation. Journal of Product \& Brand Management, 14(2), 106-116. DOI: 10.1108/10610420510592581

Hennig-Thurau, T., Gwinner, K. P., Walsh, G., \& Gremler, D. D. (2004). Electronic word-of-mouth via consumeropinion platforms: what motivates consumers to articulate themselves on the internet? Journal of interactive marketing, 18(1), DOI: 38-52. 10.1002/dir.10073 
Hennig-Thurau, T., Walsh, G., \& Walsh, G. (2003). Electronic word-of-mouth: Motives for and consequences of reading customer articulations on the Internet. International journal of electronic commerce, 8(2), 51-74. DOI: 10.1080/10864415.2003.11044293

Herr, Paul \& Kardes, Frank \& Kim, John. (1991). Effects of Word-of-Mouth and Product Attribute Information on Persuasion: An Accessibility Diagnosticity Perspective. Journal of Consumer Research. DOI: $10.1086 / 208570$

Hung, K. H., \& Li, S. Y. (2007). The influence of eWOM on virtual consumer communities: Social capital, consumer learning, and behavioral outcomes. Journal of advertising research, 47(4), 485-495.

Japutra, A., Ekinci, Y., \& Simkin, L. (2014). Exploring brand attachment, its determinants and outcomes. Journal of strategic Marketing, 22(7), 616-630. DOI: 10.1080/0965254X.2014.914062

Japutra, A., Ekinci, Y., Simkin, L., \& Nguyen, B. (2014). The dark side of brand attachment: A conceptual framework of brand attachment's detrimental outcomes. The Marketing Review, 14(3), 245-264. DOI:

10.1362/146934714X14024779061875

Lee, A. Y., \& Labroo, A. A. (2004). The effect of conceptual and perceptual fluency on brand evaluation. Journal of Marketing Research, 41(2), 151-165. DOI: 10.1509/jmkr.41.2.151.28665

Lee, M., \& Youn, S. (2009). Electronic word of mouth (eWOM) How eWOM platforms influence consumer product judgement. International Journal of Advertising, 28(3), 473-499. DOI: 10.2501/S0265048709200709
Muehling, D. D. (1987). Comparative advertising: the influence of attitudetoward-the-ad on brand evaluation. Journal of Advertising, 16(4), 43-49. DOI:10.1080/00913367.1987.10673094

Pasternak, O., Veloutsou, C. and MorganThomas, A. (2017),"Self-presentation, privacy and electronic word-of-mouth in social media", Journal of Product \& Brand. Online information review, 37(6), 910-926. DOI: 10.1108/JPBM-04-20161150

Park, C. W., Eisingerich, A. B., \& Park, J. W. (2013). From brand aversion or indifference to brand attachment: Authors' response to commentaries to Park, Eisingerich, and Park's brand attachmentaversion model. Journal of Consumer Psychology, 23(2), 269-274. DOI: 10.1016/j.jcps.2013.01.006

Park, C. W., MacInnis, D. J., \& Priester, J. (2008). Brand attachment: Constructs, consequences, and causes. Foundations and Trends in Marketing, 1(3), 191-230. DOI: 10.1561/1700000006

Park, C., \& Lee, T. M. (2009). Information direction, website reputation and eWOM effect: A moderating role of product type. Journal of Business research, 62(1), 6167. DOI: 10.1016/j.jbusres.2007.11.017

Park, D. H., \& Lee, J. (2008). eWOM overload and its effect on consumer behavioral intention depending on consumer involvement. Electronic Commerce Research and Applications, 7(4), 386-398. DOI: 10.1016/j.elerap.2016.03.004

Park, D. H., Lee, J., \& Han, I. (2007). The effect of on-line consumer reviews on consumer purchasing intention: The moderating role of involvement. International journal of electronic 
commerce, 11(4), 125-148. DOI: 10.2753/JEC1086-4415110405

Patwardhan, H., \& Balasubramanian, S. K. (2011). Brand romance: a complementary approach to explain emotional attachment toward brands. Journal of Product \& Brand Management, 20(4), 297-308. DOI: DOI: $10.1362 / 147539213 X 13645550618560$

Rabjohn, N., Cheung, C.M., \& Lee, M. (2008). Examining the Perceived Credibility of Online Opinions: Information Adoption in the Online Environment. Proceedings of the 41st Annual Hawaii International Conference on System Sciences (HICSS 2008), 286286. DOI: $10.1109 / \mathrm{HICSS} .2008 .156$

Sabate, F., Berbegal-Mirabent, J., Cañabate, A., \& Lebherz, P. R. (2014). Factors influencing popularity of branded content in Facebook fan pages. European Management Journal, 32(6), 1001-1011. DOI: 10.1016/j.emj.2014.05.001

Schivinski, B., \& Dabrowski, D. (2016). The effect of social media communication on consumer perceptions of brands. Journal of Marketing Communications, 22(2), 189-214. DOI: $10.1080 / 13527266.2013 .871323$

Schmalz, S., \& Orth, U. R. (2012). Brand attachment and consumer emotional response to unethical firm behavior. Psychology \& Marketing, 29(11), 869884. DOI: $10.1002 /$ mar.20570

Senecal, S., \& Nantel, J. (2004). The influence of online product recommendations on consumers' online choices. Journal of retailing, 80(2), 159169. DOI: 10.1016/j.jretai.2004.04.001

Smith, R. E., \& Vogt, C. A. (1995). The Effects of Integrating Advertising and Negative Word of-Mouth
Communications on Message Processing and Response. Journal of Consumer Psychology, 4(2), 133-151. DOI: 10.1207/s15327663jcp0402_03

Thomson, M., MacInnis, D. J., \& Whan Park, C. (2005). The ties that bind: Measuring the strength of consumers' emotional attachments to brands. Journal of consumer psychology, 15(1), 77-91. DOI: 10.1207/s15327663jcp1501_10

Zhang, K. Z., Benyoucef, M., \& Zhao, S. J. (2015). Consumer participation and gender differences on companies' microblogs: A brand attachment process perspective. Computers in Human Behavior, 44, 357-368. DOI:10.1016/j.chb.2014.11.068 
Madhusanka J.D.T., Weerasiri R.A.S., Karunarathne W.V.A.D., KJM, 2020, 09 (02)

\section{Appendices}

\section{Appendix A}

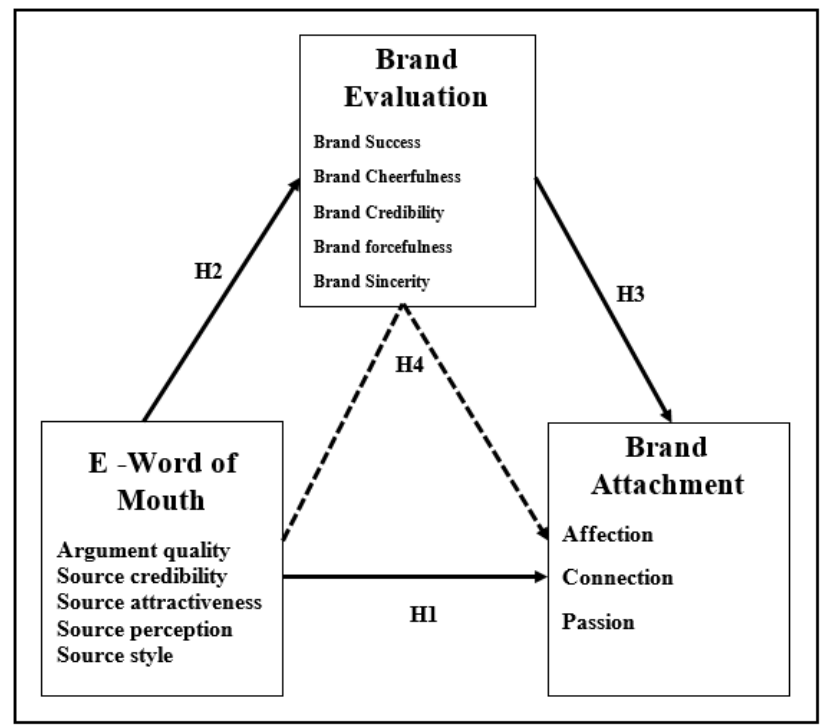

Figure 01: Conceptual Framework

\section{Appendix B}

Initial, modified and alternative structural models

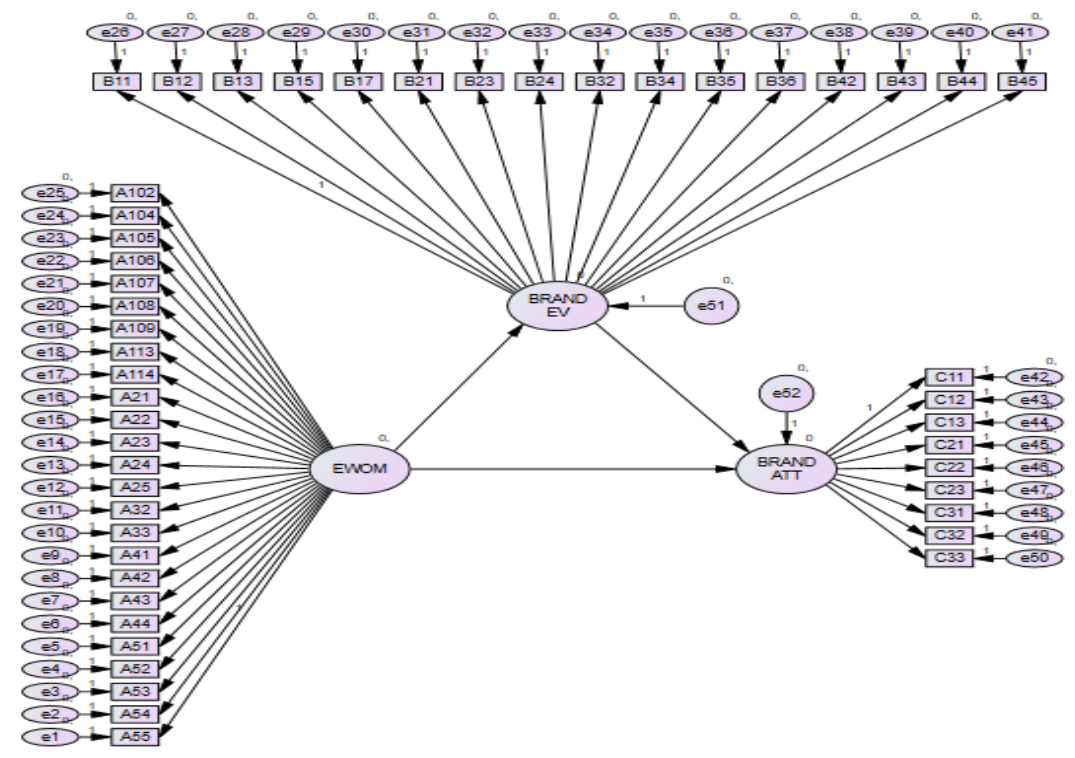

Figure 02: Initial Structural model 


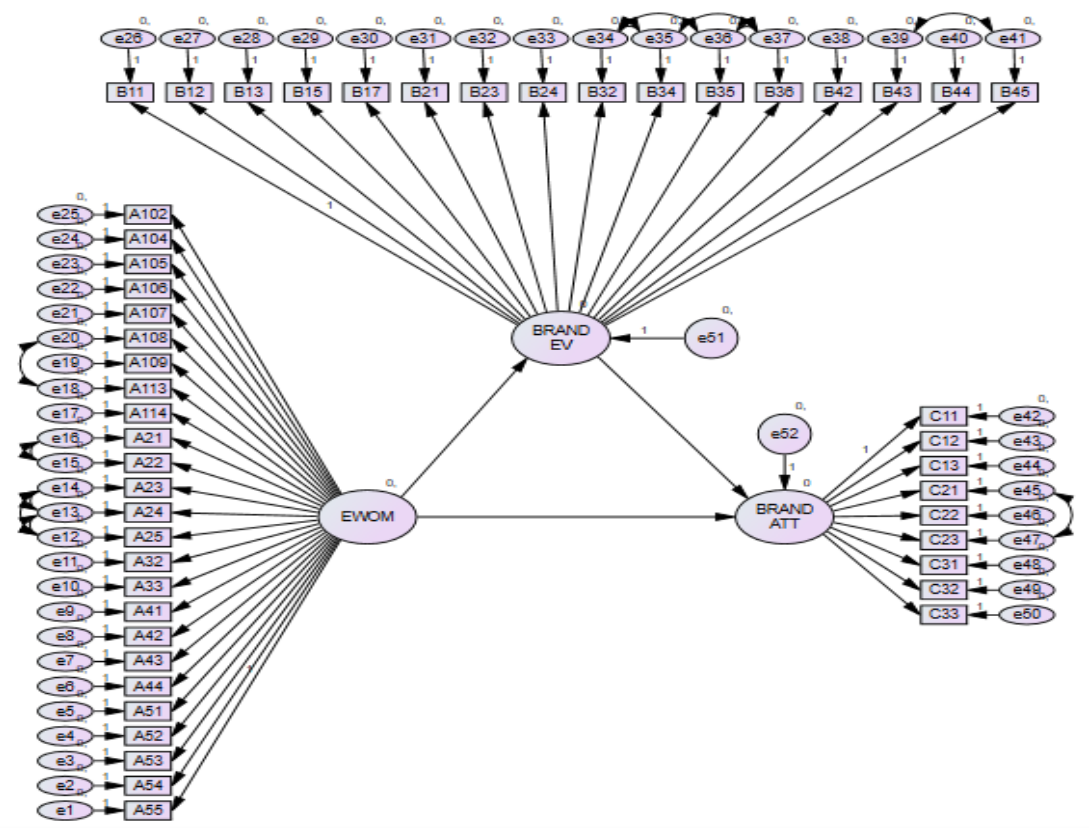

Figure 03: Modified Structural Model

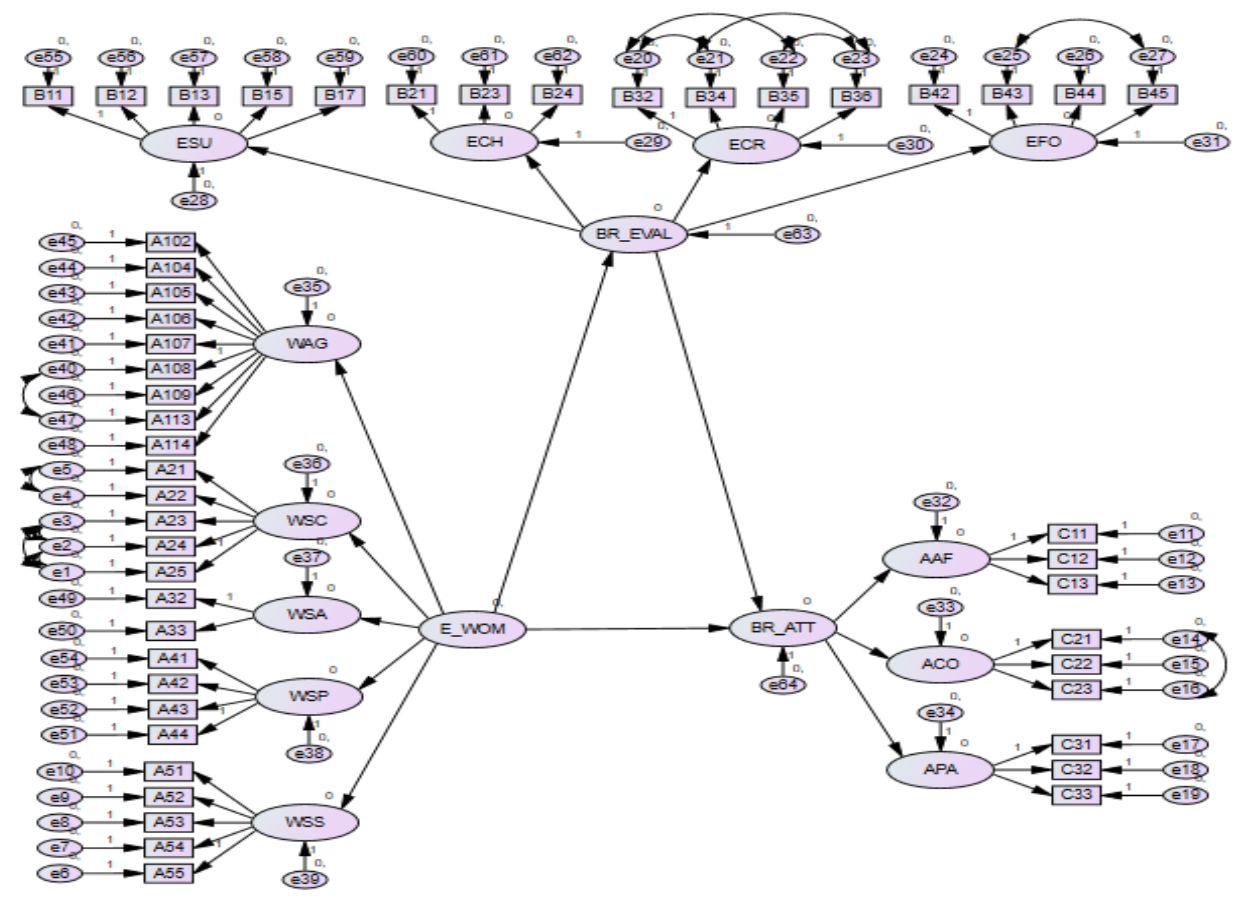

Figure 04: Alternative Structural Model (After identifying second order factors) 


\section{Appendix C}

Tables related to testing the mediation effect

Table 05: Coefficients for the Mediating Effect

\begin{tabular}{|c|c|c|c|c|c|}
\hline \multirow[b]{2}{*}{ Testing paths } & \multicolumn{2}{|c|}{$\begin{array}{l}\text { Unstandardized } \\
\text { Coefficients }\end{array}$} & \multirow{2}{*}{\begin{tabular}{|l}
$\begin{array}{l}\text { Standardized } \\
\text { Coefficients }\end{array}$ \\
Beta \\
\end{tabular}} & \multirow[b]{2}{*}{$\mathrm{T}$} & \multirow[b]{2}{*}{ Sig. } \\
\hline & B & $\begin{array}{l}\text { Std. } \\
\text { Error }\end{array}$ & & & \\
\hline \multicolumn{6}{|c|}{ Path c DV= Brand attachment } \\
\hline \multicolumn{6}{|c|}{$\mathrm{R}^{2}=0.493 \quad \mathrm{~F}=387.271 \quad \mathrm{p}=0.000$} \\
\hline $\mathrm{IV}=\mathrm{EWOM}$ & 0.601 & .031 & .702 & 19.672 & .000 \\
\hline \multicolumn{6}{|c|}{ Path a DV= Brand evaluation } \\
\hline \multicolumn{6}{|c|}{$\mathrm{R}^{2}=0.547 \quad \mathrm{~F}=481.374 \quad \mathrm{p}=0.000$} \\
\hline $\mathrm{IV}=\mathrm{EWOM}$ & .805 & .037 & .740 & 21.940 & .000 \\
\hline \multicolumn{6}{|c|}{ Path c' and b DV= Brand attachment } \\
\hline \multicolumn{6}{|c|}{$\mathrm{R}^{2}=0.606 \quad \mathrm{~F}=305.818 \mathrm{p}=0.000$} \\
\hline $\mathrm{IV}=\mathrm{EWOM}$ & 0.284 & .040 & .332 & 7.098 & .000 \\
\hline IV $=$ Brand Evaluation & 0.393 & .037 & .500 & 10.687 & .000 \\
\hline Total $(a) *(b)$ & 0.316365 & & & & \\
\hline
\end{tabular}

This table show the partial mediation effect of brand evaluation for the total data set.

Testing mediating effect related to the consumer electronic Industry

Table 06: Testing Mediating Effect Related to the Consumer Electronic Industry

\begin{tabular}{|c|c|c|c|c|c|}
\hline \multirow[b]{2}{*}{ Testing paths } & $\begin{array}{l}\text { Unst } \\
\text { Coef }\end{array}$ & & $\begin{array}{l}\text { Standardized } \\
\text { Coefficients }\end{array}$ & \multirow[b]{2}{*}{$\mathrm{T}$} & \multirow[b]{2}{*}{ Sig. } \\
\hline & B & $\begin{array}{l}\text { Std. } \\
\text { Error }\end{array}$ & Beta & & \\
\hline \multicolumn{6}{|l|}{ Path c DV= Brand attachment } \\
\hline \multicolumn{6}{|l|}{$\mathrm{R}^{2}=0.481 \quad \mathrm{~F}=182.636 \mathrm{p}=0.000$} \\
\hline $\mathrm{IV}=\mathrm{EWOM}$ & .615 & .045 & .694 & 13.514 & .000 \\
\hline \multicolumn{6}{|l|}{ Path a DV $=$ Brand evaluation } \\
\hline $\mathrm{R}^{2}=0.550 \quad \mathrm{~F}=240.551 \quad \mathrm{p}=0.000$ & & & & & \\
\hline
\end{tabular}


Madhusanka J.D.T., Weerasiri R.A.S., Karunarathne W.V.A.D., KJM, 2020, 09 (02)

\begin{tabular}{|l|l|l|l|l|l|l|}
\hline IV=EWOM & .806 & .052 & .741 & 15.510 & .000 \\
\hline \begin{tabular}{l|l|l|l|l|l|}
\hline Path c' and b DV= Brand attachment \\
\hline $\mathrm{R}^{2}=0.580 \quad \mathrm{~F}=135.310 \mathrm{p}=0.000$ & & & & \\
\hline & 0.307 & .061 & .346 & 5.017 & .000 \\
$\mathrm{IV}=$ EWOM & 0.382 & .056 & .469 & 6.793 & .000 \\
$\mathrm{IV}=$ Brand Evaluation & 0.307892 & & & & \\
\hline Total (a)*(b)
\end{tabular}
\end{tabular}

This table show the partial mediation effect of brand evaluation for the Consumer electronic industry

Testing mediating effect related to the cosmetic industry

Table 07: Testing Mediating Effect Related to the Cosmetic Industry

\begin{tabular}{|c|c|c|c|c|c|}
\hline \multirow[b]{2}{*}{ Testing paths } & \multicolumn{2}{|c|}{$\begin{array}{l}\text { Unstandardized } \\
\text { Coefficients }\end{array}$} & \multirow{2}{*}{\begin{tabular}{|l} 
Standardized \\
Coefficients
\end{tabular}} & \multirow[b]{2}{*}{$\mathrm{T}$} & \multirow[b]{2}{*}{ Sig. } \\
\hline & B & $\begin{array}{l}\text { Std. } \\
\text { Error }\end{array}$ & & & \\
\hline \multicolumn{6}{|c|}{ Path c DV= Brand attachment } \\
\hline \multicolumn{6}{|c|}{$\mathrm{R}^{2}=0.514 \quad \mathrm{~F}=210.872 \mathrm{p}=0.000$} \\
\hline $\mathrm{IV}=\mathrm{EWOM}$ & .603 & .042 & .717 & 14.521 & .000 \\
\hline \multicolumn{6}{|c|}{ Path a DV= Brand evaluation } \\
\hline \multicolumn{6}{|c|}{$\mathrm{R}^{2}=0.541 \quad \mathrm{~F}=234.409 \mathrm{p}=0.000$} \\
\hline $\mathrm{IV}=\mathrm{EWOM}$ & .809 & .053 & .735 & 15.310 & .000 \\
\hline \multicolumn{6}{|c|}{ Path c' and b DV= Brand attachment } \\
\hline \multicolumn{6}{|c|}{$\mathrm{R}^{2}=0.640 \quad \mathrm{~F}=175.987 \quad \mathrm{p}=0.000$} \\
\hline IV =EWOM & .280 & .053 & .333 & 5.288 & .000 \\
\hline IV $=$ Brand Evaluation & .400 & .048 & .523 & 8.308 & .000 \\
\hline Total $(a) *(b)$ & 0.3236 & & & & \\
\hline
\end{tabular}

This table show the partial mediation effect of brand evaluation for the cosmetic industry. 